\title{
DE LA AUTONOMÍA POLÍTICA Y CULTURAL DE LA PROVINCIA DE RÍO BEC
}

\author{
Philippe Nondédéo, ${ }^{*}$ Julie Patrois, ${ }^{*}$ Alfonso Lacadena, ${ }^{* *}$ \\ M. Charlotte Arnauld," Eric Taladoire*" y Dominique Michelet* \\ * Centre National de la Recherche Scientifique, UME 8096 \\ *** Universidad Complutense de Madrid
}

\begin{abstract}
Resumen: Ubicada en el corazón de la península de Yucatán, a medio camino entre Dzibanché y Calakmul (las dos probables sedes de la dinastía Kaan durante el Clásico), la región Río Bec, tan atípica por su patrón de asentamiento, su arquitectura y su iconografía, plantea un problema en este nuevo contexto estratégico-político. Dada su posición central entre las dos sedes, dicha región podría haber formado parte del reino Kaan en un momento u otro de su historia. Para tratar de contestar esta interrogante, y considerando la casi total ausencia de inscripciones en la región, se hizo una revisión de los datos arqueológicos disponibles, confrontándolos en la medida de lo posible con datos históricos. Al analizar de manera diacrónica la cultura material de la región, todo parece indicar que Río Bec tuvo un desarrollo propio, linear y continuo, independiente de la gran urbe de Calakmul en tiempos de la dinastía mencionada.
\end{abstract}

Palabras clave: región Río Bec, reino Kaan, Becán, Dzibanché, Calakmul.

AвSTRACT: Located in the heart of the Yucatan peninsula halfway between Dzibanche and Calakmul, both plausible seats for the Kaan dynasty at distinct moments during the Classic period, the Rio Bec region rouses a real interest because of its intermediate position in this newly-defined political context. It is legitimate to ask whether this region, with its atypical settlement pattern, architecture and iconography, was or not part of the Snake polity (or Kaan kingdom). In the absence of inscriptions in the Rio Bec region, all available data on material culture must be interrogated and compared to the historical information relative to the political context. The diachronic analysis of archaeological data strongly suggests that the Rio Bec trajectory has been linear and continuous, and that it developed independently from the huge city of Calakmul at least while it was the Kaan capital.

KeYwords: Rio Bec Region, Kaan Kingdom, Becan, Dzibanche, Calakmul.

RECEPCIÓN: 9 de junio de 2010.

ACEPTACIÓn: 30 de agosto de 2010. 



\title{
DE LA AUTONOMÍA POLÍTICA Y CULTURAL DE LA PROVINCIA DE RÍO BEC
}

\author{
Philippe Nondédéo, " Julie Patrois, , Alfonso Lacadena, \\ M. Charlotte Arnauld, " Eric Taladoire*" y Dominique Michelet* \\ *Centre National de la Recherche Scientifique, UME 8096 \\ ***Universidad Complutense de Madrid
}

\section{Introducción}

Con los avances recientes en el desciframiento y la comprensión de los textos jeroglíficos mayas, la región Río Bec se halla al centro de un escenario estratégico-político que cubre gran parte del periodo Clásico. Con base en las interpretaciones acerca del reino de Kaan (realizadas a partir de las inscripciones asociadas con los famosos cautivos de Dzibanché), la región Río Bec, atípica en muchos de sus aspectos, ha sido ubicada en una posición importante ya que se sitúa a medio camino entre Dzibanché y Calakmul, las dos posibles sedes de uno de los reinos más poderosos del periodo Clásico. Según los epigrafistas (Grube, 2004; Velásquez García, 2004; Martin, 2005), existe una serie de argumentos a favor de un posible traslado de la sede de Kaan desde Dzibanché hasta Calakmul al final del Clásico Temprano. De origen desconocido, pero tal vez procediendo de la Cuenca del Mirador (Beliaev y Safronov, 2002; Grube, 2004; Martin, 2005; Šprajc y Grube, 2008), la dinastía Kaan se habría establecido por un poco más de un siglo en Dzibanché (aproximadamente entre el 450 y el 573 d.C.) antes de ocupar por un periodo de tiempo equivalente la ciudad de Calakmul entre el 631 y el 736 d.C. (Martin, 2005; Nalda, 2010; Nalda y Balanzario, 2008; Velásquez García, 2008).

Con independencia de que las interpretaciones de los textos —escasos y a veces difíciles de entender por lo oscuro de las expresiones empleadas, la pérdida de información en parte borrada, o la presencia de glifos aún sin descifrar- reflejen o no la realidad política en las Tierras Bajas, esta hipótesis de un cambio de sede dinástica nos obliga a cuestionarnos sobre el posible papel e impacto de la dinastía Kaan, y de Calakmul en particular, sobre el desarrollo de la región Río Bec, a la vez tan cerca y tan diferente de dicha capital regional. Cabe agregar que han sido documentadas menciones de Kaan en varios de los sitios importantes ubicados en la periferia de dicha región: Dzibanché, Resbalón, Pol Box, Los Alacranes (Martin y Grube, 2000; Esparza y Pérez, 2009), y posiblemente se haría en otros más, como Balamkú o Nadzca'an, si las inscripciones no estuvieran borradas (figura 1). Esta serie de menciones parece indicar que extender el control de Kaan sobre Río Bec no habría representado mayor dificultad para tal dinastía, 
ni tampoco una inversión político-militar desmedida para el sitio capital, la que haya sido, pues Kaan fue capaz de establecer una red compleja y densa de alianzas y organizar campañas militares hacia sitios mucho más alejados hacia el sur (Palenque, Toniná o Yaxchilán).

Frente a esta potencia, con sus dos posibles sedes sucesivas ubicadas en la cercanía de la región Río Bec, surge una serie de preguntas: ¿cómo se sitúa esta región en el contexto político del Clásico Temprano-Clásico Tardío? ¿Formó parte del territorio de Kaan en un momento o en otro o bien fue un territorio más o menos autónomo, de poco interés político para Kaan por la ausencia de producción de riquezas y de concentraciones significativas de población? ¿Cómo se manifestaría en el registro arqueológico el dominio o la ausencia de dominio de Kaan sobre Río Bec? Para tratar de formular ideas nuevas sobre este tema espinoso, se requiere una reevaluación diacrónica de los datos disponibles acerca de la cultura material de la región, confrontándolos, cada vez que sea posible, con los avances históricos sobre la dinastía Kaan. Para eso utilizaremos en particular los datos recientes proporcionados por el Proyecto Río Bec enfocado en la microrregión que rodea al "sitio" homónimo (figura 2), así como los que han sido recogidos por Luz Evelia Campaña en Becán.

La reevaluación de la cultura material en relación con el registro históricoepigráfico regional es posible si se toman en consideración dos hipótesis: por un lado, se puede suponer que la cultura material Río Bec debería reflejar la soberanía efectiva de Kaan debida a un aumento de intercambios regionales, es decir, por la afluencia relativa de bienes de comercio a mediana y larga distancia; por el otro, y a la inversa, pocas importaciones deberían haberse dado en el caso de la independencia o autonomía de Río Bec. Conforme a la segunda hipótesis también, el auge de la arquitectura monumental Río Bec correspondería a una situación en la que sus grupos de élite gozarían de cierto grado de autonomía frente a la dinastía más potente.

\section{La región Río Bec}

Ocupa grosso modo el centro de la península y se extiende sobre una superficie de aproximadamente $6500 \mathrm{~km}^{2}$. Se trata de una región culturalmente atípica $a$ priori pues muestra un patrón de asentamiento bastante disperso, constituido esencialmente por pequeños grupos monumentales y sin verdaderas concentraciones mayores de población, excepción hecha de Becán, el único sitio que se puede comparar con los demás centros de las Tierras Bajas (Nondédéo, en prensa). A la par de esta forma de organización sociopolítica bastante atomizada en una región, a final de cuentas esencialmente rural, va la casi ausencia de inscripciones glíficas (Nondédéo y Patrois, 2007: 163-168; Taladoire, 2009). El tamaño reducido de los grupos (menos de 10 estructuras en promedio), junto con el desarrollo sociopolítico limitado que ellos ejemplifican, dan cuenta de la ausen- 


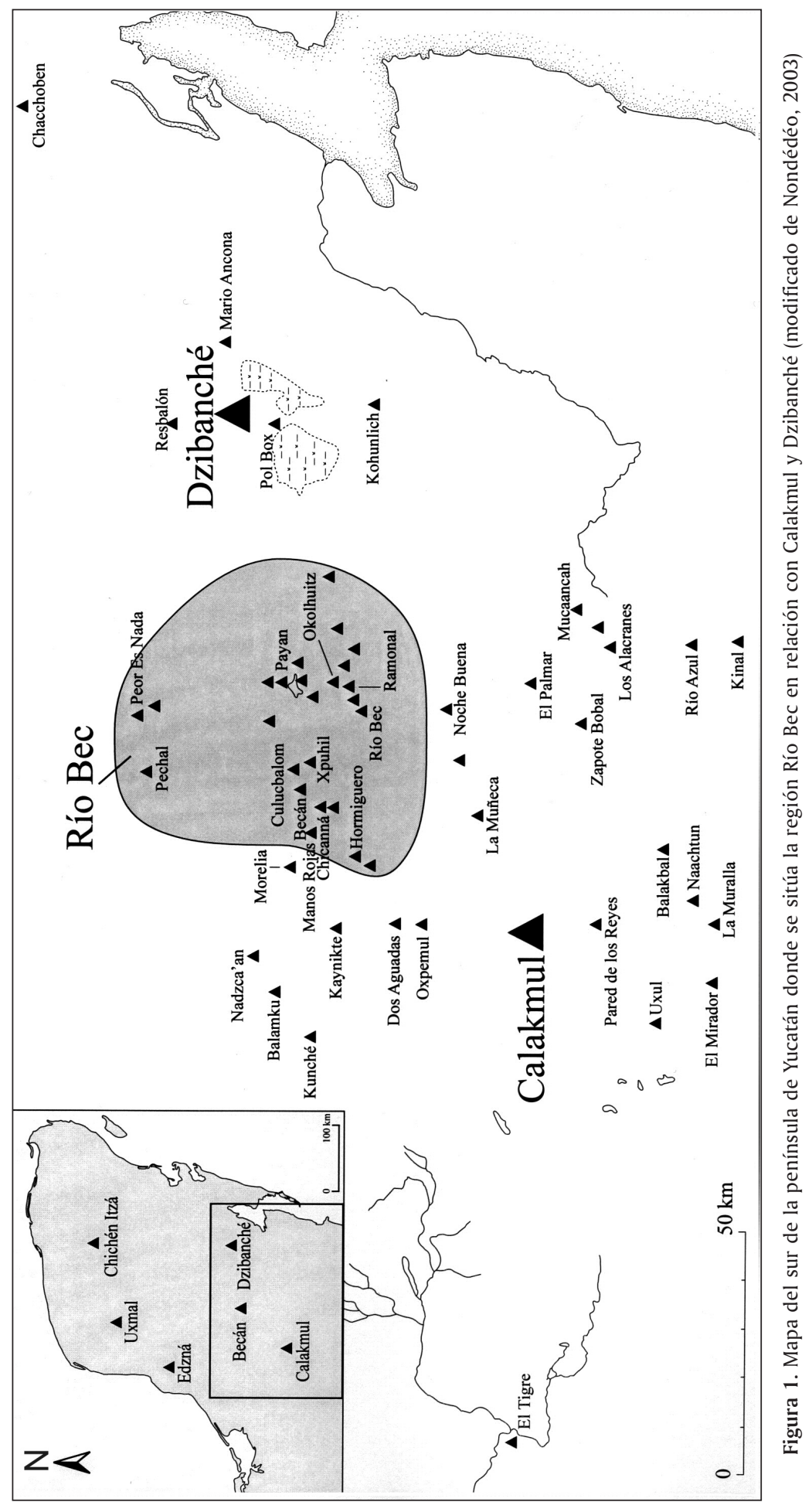




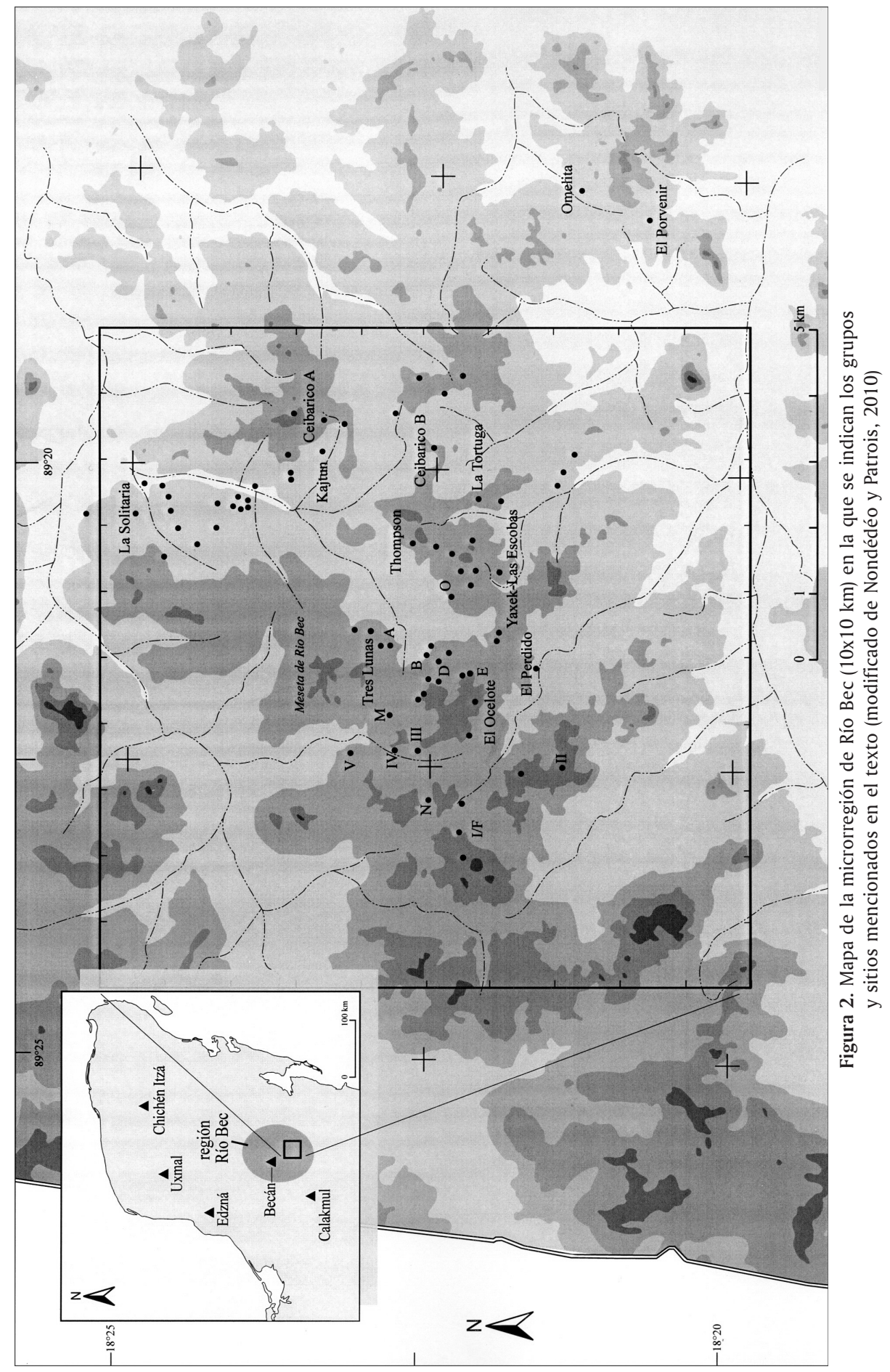


cia de una entidad política real estable en los sitios de la región. La falta de arraigo de los linajes o casas nobles locales se refleja en la trayectoria discontinua de los asentamientos de la región, un fenómeno que impidió el fortalecimiento y la consolidación de los linajes existentes (Nondédéo y Dzul, en prensa). En efecto, después de una ocupación leve y dispersa durante el Preclásico, sin centros importantes capaces de atraer a una población importante (con excepción tal vez de Becán y, a una escala menor, de Kajtún y del Grupo II de Río Bec mismo), la región Río Bec empieza realmente a desarrollarse a finales del Clásico Temprano con la aparición de las primeras manifestaciones arquitectónicas e iconográficas del nuevo estilo. Pero se produce entonces una especie de ruptura en la ocupación: declinan o se abandonan algunos de los centros anteriores (Grupo II, Kajtún) y se funda toda una serie de nuevos asentamientos de pequeño tamaño en los que se desarrolla el estilo Río Bec. La ocupación limitada temporal y/o espacialmente de estos nuevos grupos frenó seguramente el establecimiento de familias locales fuertes, y en particular impidió a sus jefes alcanzar el rango de ajaw aunque, en ciertos casos, a través de representaciones de escenas de corte, se percibe un fuerte deseo por parte de algunos de ellos de actuar como si lo fueran (Arnauld y Lacadena, 2004).

Ahora bien, reponiendo la trayectoria del fenómeno Río Bec dentro de un contexto macroregional, su aparición alrededor de los años 550 y 600 d.C. coincide con el declive de Dzibanché, el cual inicia según Nalda y Balanzario (2008: 312) a principios del Clásico Tardío. La región Río Bec se desarrolla durante la primera parte del Clásico Tardío - lo que coincide con la máxima expansión del reino de Kaan establecido ahora en Calakmul - y alcanza su apogeo en la segunda mitad de este mismo periodo y en la transición con el Clásico Terminal, o sea, más de un siglo después de la última mención de esta dinastía en Calakmul.

\section{Kaan y la génesis del fenómeno Río Bec}

Para evaluar las eventuales relaciones entre el reino de Kaan y Río Bec durante el Clásico Tardío, es preciso regresar al Clásico Temprano, momento clave de génesis del fenómeno Río Bec. Durante la primera mitad de este periodo, pocos asentamientos muestran claras evidencias de ocupación y construcción. Se han detectado contadas huellas de actividad en algunos sitios pequeños: en Hormiguero, alrededor de la Estructura I o en la Estructura V sub (Bueno, 1989: 65, 108); en Chicanná, en la Plaza A (Carrasco, 1994: 148); mientras que en otros, como Kajtún y el Grupo II, construcciones más importantes derivan de una ocupación substancial en el Preclásico Medio y Tardío (Nondédéo y Lacadena, 2004; Nondédéo y Dzul, en prensa). El Grupo II, uno de los más activos políticamente en la parte sur de la región Río Bec, tuvo un desarrollo lo suficientemente importante como para erigir la Estela 5, fechada en el 475 d.C. (Lacadena, 2007). Esta estela, aunque sólo conservada en su tercio inferior, sigue los cánones del 
estilo Petén y representa a un gobernante de pie acompañado por un cautivo. Es la única con fecha del Clásico Temprano que se encuentra en el territorio que corresponderá más tarde al de la región Río Bec (tabla 1). La dedicación de esta estela antecede en dos décadas a las más antiguas menciones de Kaan en el sur de Campeche y Quintana Roo (Velásquez, 2008), por lo que no se puede relacionar, al menos por el momento, la historia del Grupo II con aquella dinastía.

El sitio más importante y más dinámico de la región, a pesar de la ausencia de estelas con inscripción correspondientes al Clásico Temprano, es sin lugar a dudas Becán. ${ }^{1}$ Al igual que Kajtún o el Grupo II, Becán conoció una fuerte actividad durante el Preclásico Tardío, fenómeno particularmente evidente con la edificación de las Estructuras II sub, IV sub y, sobre todo, la Pirámide IX (Bueno et al., 1992; Ball y Andrews, 1978; Campaña Valenzuela y Boucher, 2002), sin hablar del famoso foso cuya datación verosímil del Preclásico Tardío no ha sido claramente establecida ${ }^{2}$ (Web-

\begin{tabular}{|c|c|c|}
\hline Sitio & Monumento & Fecha \\
\hline Río Bec II & Estela 5 & (475 d.C.) \\
\hline Río Bec V & Estela 3 & 9.9.0.0.0? \\
\hline Río Bec II & Estela 3 & (672 d.C.) \\
\hline Kajtun & Estela 4 & (731 d.C.) \\
\hline Río Bec V & Estela 6 & 9.18.0.0.0? \\
\hline San Lorenzo & Estela 1 & (790 d.C.) \\
\hline Kajtun & Estela 5 & (795 d.C.) \\
\hline Río Bec B & Banqueta norte & 9.18 .15 .0 .0 \\
\hline Becan & Estela 10 & entre 9.15 y 10.1 por el estilo \\
\hline Río Bec V & Estela 2 & (869 d.C.) \\
\hline Pasión del Cristo & Estela 2 & (889 d.C.) \\
\hline Pasión del Cristo & Estela 1 & 10.3.10.0.0 \\
\hline Pechal & Estela 1 & Clásico Terminal por el estilo \\
\hline Pechal & Estela 2 & Clásico Terminal por el estilo \\
\hline Pechal & Estela 3 & Clásico Terminal por el estilo \\
\hline
\end{tabular}

Tabla 1. Estelas con inscripciones y fechas en la región Río Bec (información basada en Bueno, 1999; Nondédéo, 2003; Lacadena, 2007)

${ }^{1}$ En su estudio del patrón de asentamiento en la periferia de Becán, Thomas (1981: 23) señala que la Estela 5, ubicada al oeste del Grupo Mundo Perdido y desafortunadamente lisa, está relacionada con un piso de estuco fechado de la fase Chacsik (250-450 d.C.).

${ }^{2}$ Además de drenar los terrenos inundados situados al norte del sitio en dirección de la gran aguada ubicada al sur (Campaña Valenzuela, 2005: 49), una de las principales funciones del foso de Becán fue la de cantera gigantesca para las construcciones de los edificios de la ciudad. A nuestro juicio, esta cantera pudo haber estado en uso durante distintas épocas de la historia del sitio, lo que dificulta el fechamiento de su construcción inicial. Tal como lo demostró Campaña Valenzuela (2005: 50) en sus excavaciones, el error de interpretación de los montículos situados a lo largo del foso (en realidad, unidades residenciales modestas) como parapetos o murallas que complementarían el sistema defensivo del foso, obligaría a reevaluar la concepción bélica de dicho elemento arquitectónico. Además, particularmente en el sector noreste, el foso se convirtió durante la fase Bejuco en un enorme basurero relacionado con estas modestas viviendas cercanas y con el imponente Complejo XIII (Ball, 1977: 177). 
ster, 1976; Bueno, 1999). Según Campaña (2005; Campaña Valenzuela et al., 2000, 2001, 2004; Campaña Valenzuela y Tiesler, 2004), durante la primera fase del Clásico Temprano, fase Chacsik (250-450 d. C.), se emprenden en Becán numerosas construcciones: la plataforma superior de la Pirámide IX, junto con una serie importante de palacios: el Palacio W1, de 22 cuartos, en gran parte rellenado al construir el Edificio X del Clásico Tardío; la Estructura 2 sub en el patio norte del Conjunto X; la Estructura I sub y posiblemente gran parte del Complejo XIII, ubicado en el extremo oeste del recinto (figura 3a). De esta misma fase data también el famoso depósito funerario encontrado en la plataforma superior de la Pirámide IX, así como el friso de estuco que decora el edificio 2 del Patio X sur (Campaña Valenzuela y Boucher, 2002; Boucher, Palomo y Campaña Valenzuela, 2004).

Durante esta fase, y probablemente durante una parte de la fase siguiente, la región Río Bec estuvo interactuando con el resto de las Tierras Bajas. Recibe influencias de toda índole y bienes de prestigio procedentes del Petén central, de Calakmul y de Belice (Ball, 1977: 169). Dicho de otra manera, durante gran parte del Clásico Temprano la región Río Bec, en todos los aspectos de su cultura material (patrón de asentamiento, iconografía, cerámica, arquitectura, tradición funeraria...), se debe considerar vinculada con la tradición petenera (Nondédéo, 2003). ${ }^{3}$ Por otra parte, no se percibe en ella evidencia alguna de control de Kaan, cualquiera que haya sido su sede. La presencia, en el depósito de la Estructura IX, de cerámicas relacionadas estilística y técnicamente tanto con Calakmul como con Tikal (Campaña Valenzuela, 2005: 51) podría indicar, según Boucher, Palomo y Campaña Valenzuela (2004), contactos estrechos y seguidos con estos dos sitios, pero no de naturaleza que permita inferir control alguno de uno u otro de ellos sobre Becán. Asimismo, el estilo iconográfico del friso estucado que decora el edificio 2 del Patio X sur no se puede relacionar con un sitio en particular.

En la segunda mitad del Clásico Temprano, en la fase Sabucán (450-630 d.C.), la situación en la región se descubre distinta, y contrastada según los sitios. En el sitio emblemático de Becán, al dinamismo observado en la fase anterior sucede un tiempo bastante mal definido: al revisar el corpus de datos disponibles, no nos ha sido posible identificar una sola construcción significativa de esta fase, como si se hubiera producido una ruptura con la anterior. De hecho, el único evento relevante, que contrasta además de cierta manera con la disminución drástica de la actividad constructiva señalada, es el hallazgo, en la modesta Estructura XIV sub (cuarto 3), de la famosa ofrenda dedicatoria de tipo Teotihuacan

\footnotetext{
${ }^{3}$ La tradición Petén reúne un conjunto de rasgos originarios y que se observan en la arquitectura, la iconografía, la organización espacial de los sitios, la cerámica, las prácticas funerarias, etc. Estos rasgos alcanzan las regiones más al norte de la península a través de los sitios del Petén campechano que difunden estas influencias. En este último fenómeno, un sitio como Calakmul parece haber desempeñado un papel fundamental. Tanto en el sur de Campeche como en el sur de Quintana Roo, esta tradición petenera se nota sobre todo durante el Preclásico Tardío y la primera mitad del Clásico Temprano antes de desaparecer paulatinamente en beneficio de tradiciones más bien locales (Nondédéo, 2003).
} 


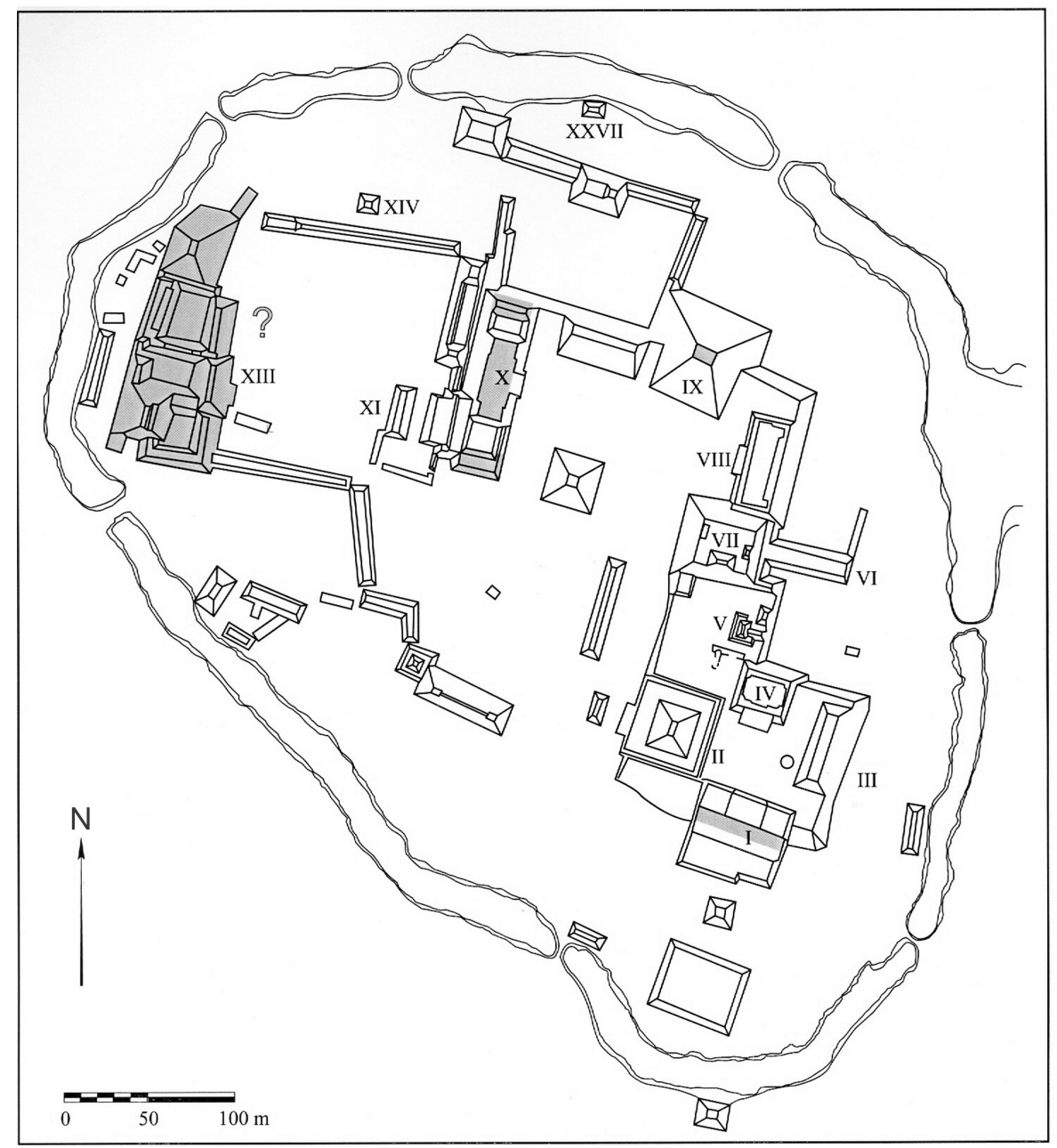

Figura 3a. Becán durante el Clásico Temprano (fase Chacsik: 250-450 d.C.)

(Ball, 1977: 100-101). Es por ahora difícil relacionar este hallazgo aislado con la historia de un sitio que parece caer de repente en estado de letargo. ${ }^{4}$

A nivel regional, lo que caracteriza la fase Sabucán son, sin lugar a dudas, los cambios sociales y políticos importantes que sufre la región y que habría que relacionar con la gestación del fenómeno Río Bec. Estos cambios sociopolíticos se observan de manera bastante clara en la periferia inmediata de Becán y se re-

${ }^{4}$ Aunque aparentemente abundante según Ball (1977: 132), el material cerámico de la fase Sabucán apareció en pocas cantidades en los proyectos recientes, y eso a pesar de sus dimensiones (Dzul en Campaña, Angulo et al., 2001). 
flejan ante todo en la adopción de un nuevo patrón de asentamiento: se abandonan los grupos-patios y grupos-plazuelas ocupados anteriormente y se organiza una red de unidades residenciales muy dispersas en un contexto rural (Thomas, 1981: 99). Esta reorganización del asentamiento introduce una ruptura radical con el patrón anterior y constituye el primer signo tangible del establecimiento de la tradición Río Bec en la región, ya que este nuevo patrón va a caracterizar también a la primera mitad del Clásico Tardío (fase Bejuco). En la micro-región de Río Bec, estos cambios en el patrón de asentamiento no son tan obvios, tal vez porque nunca hubo antes un grado de nucleación equiparable con el de Becán. Sin embargo, se observa la caída de la actividad en ciertos asentamientos antiguos importantes como Kajtún o El Grupo II, la multiplicación de unidades residenciales dispersas y la fundación de varios grupos monumentales que van a difundir en la fase siguiente la nueva tradición arquitectónica (Taladoire y Dzul, en prensa; Nondédéo y Dzul, en prensa). Además, en ambos lugares (Becán y la microrregión de Río Bec) esta segunda fase del Clásico Temprano, junto con la primera mitad del Clásico Tardío, parece constituir un apogeo en términos de densidad poblacional (Thomas, 1981: 100-101; Nondédéo y Dzul, 2007; Taladoire, 2007). Por otro lado, si en Becán el complejo cerámico Sabucán aún refleja una fuerte influencia del Petén en los tipos (Ball, 1977: 171), en cambio, dentro de la microrregión de Río Bec, y en el complejo equivalente, Iximché (425-550 d.C.), Sara Dzul observó por primera vez una verdadera identidad cerámica Río Bec con modas particulares influenciadas en parte por tradiciones del norte de la península.

Cualquiera que haya sido la causa de estos cambios, parece ocurrir en un periodo bastante confuso y agitado: Thomas (1981: 99-100), para explicar el abandono total y generalizado de los grupos-plazuelas alrededor del recinto de Becán, evoca un fenómeno de desaparición de las élites Pakluum-Chacsik. Por su parte, Ball (1977: 170-171) menciona la presencia inhabitual y particularmente elevada de restos óseos en los rellenos constructivos que presentan un fuerte componente de la fase Sabucán; este hecho reflejaría cierto desequilibrio. Desde un punto de vista epigráfico-histórico, esta fase Sabucán corresponde también a cambios importantes y a un periodo de desequilibrio. Por una parte, se trata de la instalación probable de la dinastía Kaan en la región (¿en Dzibanché?) y, por otra, de la expansión progresiva de su dominio regional por medio de conquistas y de una política activa de alianzas, en particular con El Resbalón, Pol Box o Los Alacranes, todos sitios que circundan a la región Río Bec (Martin y Grube, 2000: 103-104; Velásquez García, 2008). En este contexto, uno se puede preguntar en qué medida la desaparición de las élites en la periferia de Becán, junto con la interrupción de los programas de construcción en el centro mismo, tendrían algo que ver con la instalación de Kaan en las inmediaciones de la región y con la extensión de su poder por medio de acciones belicosas. 


\section{La región Río Bec durante el Clásico Tardío}

Fuera lo que fuera, el patrón disperso que apareció en la segunda parte del Clásico Temprano también caracteriza a la primera mitad del Clásico Tardío (fase Bejuco: 630-730 d.C.). Tal vez refleje, durante un periodo de casi 200 años (aproximadamente entre el 550 y el 730 d.C.), cierto sentimiento de seguridad en la región o, más bien, una ausencia de amenazas en un momento clave de la historia de las Tierras Bajas. Efectivamente, ocurre entonces, por un lado, la caída de Dzibanché — marcada, según Nalda (2010; Nalda y Balanzario, 2008), por una serie de profanaciones y destrucciones, una interrupción de las construcciones monumentales y un despoblamiento progresivo de la ciudad-, y, por el otro, el establecimiento de la dinastía Kaan en Calakmul (Martin, 2005). Estos acontecimientos, probablemente en parte violentos, deberían haberse reflejado de una manera o de otra en la región Río Bec si ésta hubiera estado supeditada políticamente a la dinastía Kaan.

Si por una parte, cabe la hipótesis de relacionar la ausencia de amenazas en la región con una pertenencia de Río Bec a la hegemonía de Kaan, lo que lo protegería en cierta manera de ataques de entidades enemigas, por otra, los datos arqueológicos indican que, conforme se desarrollaron los rasgos Río Bec y se construyeron los nuevos edificios, la región se desconecta del resto de las Tierras Bajas. De hecho, tiende a aislarse cada vez más, produciendo su propia cerámica y recibiendo cada vez menos productos importados de cerámica, pedernal, jade u obsidiana (Ball, 1977: 171-172; Stoltman, 1978: 16-19; Rovner y Lewenstein, 1997: 129-130; Andrieu, 2007). Este fenómeno de aislamiento, de autarquía en el que entra la región, parece ir en contra de cualquier control de Kaan sobre Río Bec ya que, en este último caso, se esperaría encontrar, además de un acceso más fácil a las redes de intercambios, bienes de prestigio procedentes de Calakmul, frutos de cierta redistribución o regalos en el marco de eventos político-sociales.

El aislamiento de Río Bec coincide con la aparición de los rasgos típicos de la región y la construcción de los primeros edificios diagnósticos del nuevo estilo, ilustrados por las portadas zoomorfas, en particular en la Estructura X de Becán (Campaña Valenzuela y Boucher, 2002). Durante la fase Bejuco (630-730 d.C.), Becán fue profundamente remodelado: se adosaron nuevos cuerpos a la Pirámide IX y se construyó una cancha de juego de pelota (Estructura XI) (figura 3b). Se edifica también una serie de residencias para las élites: el nivel inferior (este) de la Estructura II, el nivel 2 de la Estructura IV y la Estructura V-a (Bueno, et al. 1992; Bueno, 1999; Messenger, 1975: 73-74). Durante esta fase, en vez de hacerse evidente cualquier dominio de Kaan en Becán, se reinicia allí un desarrollo y se alcanza un florecimiento: el sitio parece posicionarse como la referencia, el modelo a imitar para toda la región. Y, efectivamente, este dinamismo encuentra un eco en varios sitios de la región: en Chicanná se construyen la Estructura I (los seis cuartos de la fachada, sin las torres) y la Estructura VI (Eaton, 1975: 
133; Carrasco, 1994), mientras que en Hormiguero se edifica probablemente la Estructura 57 con sus cascadas de mascarones apilados (Bueno, 1987, 1991). En la microrregión de Río Bec (fase Kanlol: 550-700 d.C.), se fundan de manera casi simultánea numerosos grupos monumentales, todos con un edificio principal, del tipo multicámara: La Solitaria, Estructura 1; Yaxek-Las Escobas, Estructura 5; El Perdido, Estructura 1; Ceibarico B, Estructura 1, entre otros (Nondédéo y Dzul, 2007).

A partir de los datos relativos a la ocupación y a la construcción de edificios, la evolución de la región en su conjunto parece ahora ininterrumpida y linear, reuniéndose las condiciones para un apogeo en la fase siguiente. En el registro epigráfico, las pocas estelas erigidas en esta fase con fechas legibles no indican relación alguna con Kaan: parecen más bien inscribirse dentro de una historia local. Del lado de Calakmul, por otra parte, no existen para la primera mitad del

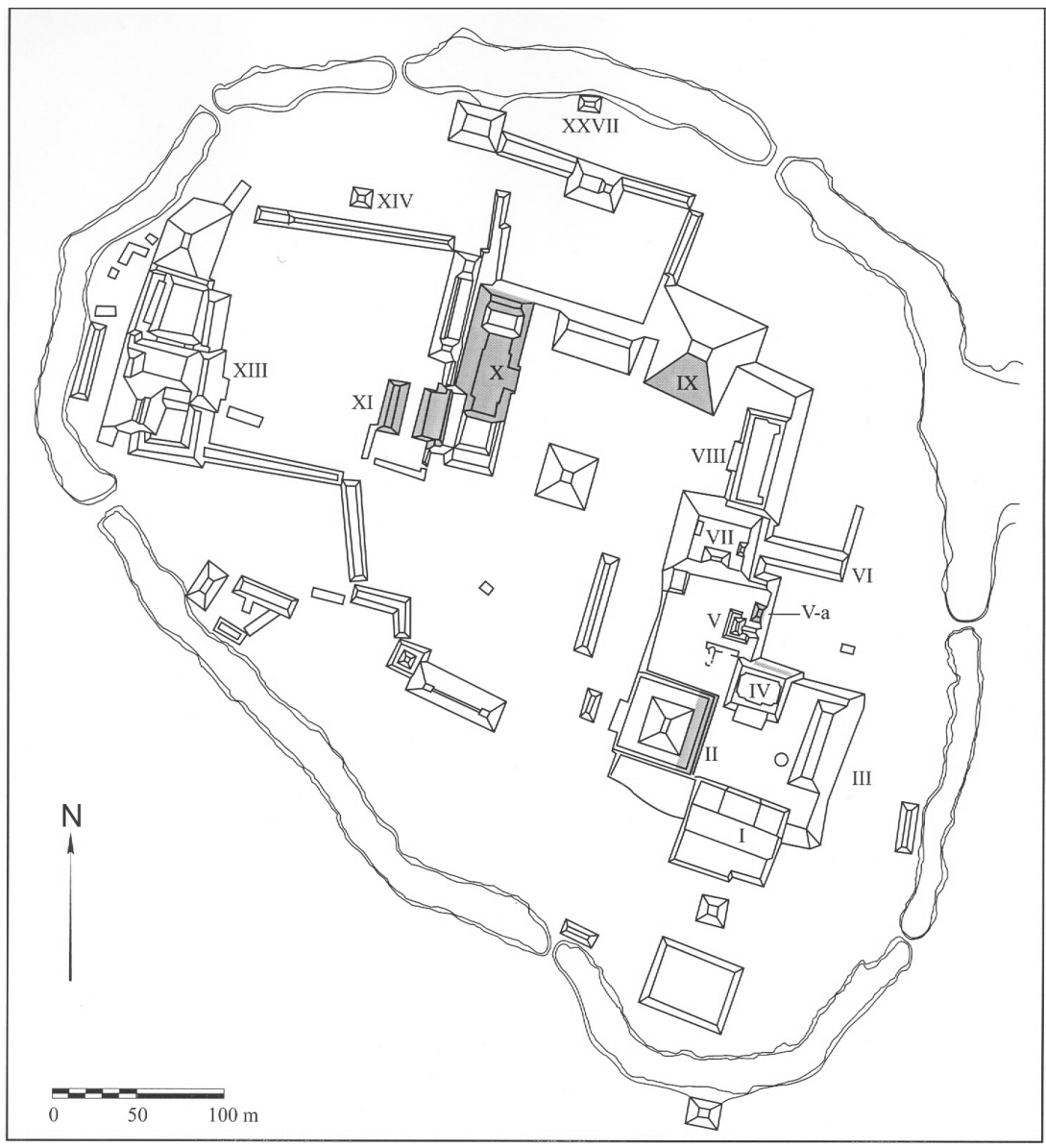

Figura 3b. Becán durante el Clásico Tardío (fase Bejuco: 630-730 d.C.) 
Clásico Tardío elementos de influencia Río Bec, que indicarían relaciones, intercambios o contactos entre ambas regiones. ${ }^{5}$

\section{Río Bec después de la dinastía Kaan}

La segunda fase del Clásico Tardío (Chintok: 730-830 d.C.) corresponde en Río Bec al apogeo en términos de construcciones. Coincide con la caída de la dinastía Kaan después de la derrota en el 736 d.C. de Calakmul contra Tikal (Martin, 2005). Se podría pensar, a primera vista, en una relación de causa-efecto entre estos dos acontecimientos, en la caída de Kaan liberando la región Río Bec del yugo de Calakmul y permitiendo su auge. Sin embargo, el análisis de la cultura material sugiere una historia diferente. En efecto, la segunda mitad del Clásico Tardío corresponde al momento de mayor aislamiento de Río Bec, lo cual se descubre en la suspensión de los intercambios visibles, en particular en la desaparición total de las pocas cerámicas finas que aún alcanzaban la región. Al mismo tiempo, esta fase se caracteriza por una regresión a nivel cerámico, tanto en la calidad como en la variedad de los tipos (Ball, 1977: 133-134). Desde el punto de vista de la ocupación, es posible constatar un abandono progresivo de las unidades más dispersas y aisladas y la concentración de la población justo en o en las proximidades de los grupos monumentales que entonces florecen (Thomas, 1981: 102; Taladoire, 2007). No se puede determinar si estos cambios se deben relacionar con un sentimiento de inseguridad o bien si se trata de un control mayor por parte de las élites sobre la población campesina, es decir, la mano de obra para la construcción de sus palacios. El fenómeno de agrupamiento de la población se nota de manera muy clara en la periferia de Becán donde se vuelven a ocupar los antiguos grupos-plazuelas del Clásico Temprano, pero requiere todavía más análisis en el caso de la microrregión de Río Bec. Allí, una tendencia análoga ha sido observada en un contexto habitacional relativamente distinto, ya que es de carácter más rural (Taladoire, 2007).

La fase Chintok se ilustra ante todo mediante el desarrollo de las élites en la región. Este punto, sumamente llamativo, se percibe a través de la cantidad elevada de palacios y residencias de alto rango que se edifican. Todo ello se ilustra de manera muy clara en Becán con la construcción de conjuntos residenciales por todas partes (figura 3c). Así, en la Plaza Este se levantan los niveles 3 y 4 de la Estructura IV, así como una galería de cuartos sub debajo de la Estructura

\footnotetext{
${ }^{5}$ La estructura XX sub de Calakmul, fechada en la primera mitad del Clásico Tardío (Carrasco y Colón, 2005), está decorada a nivel del friso del techo con elementos modelados en estuco que recuerdan, según Reyes Ayala (2006), las portadas zoomorfas de Río Bec. Los pocos fragmentos conservados no nos permiten relacionar claramente esta decoración de fachada con una influencia de la mencionada región. Además, la morfología de este edificio — con dos cuartos muy alargados (35 m de largo) y abierto por siete puertas en su fachada este (Reyes Ayala, 2006) - tampoco es muy característica de la región Río Bec.
} 
I (Ball y Andrews V, 1978; Campaña Valenzuela, 2005). En la plaza central se adosan cuatro niveles de cuartos que flanquean la escalera de la Pirámide IX, mientras que el mayor esfuerzo concierne sin duda alguna a la construcción del gran Complejo X, el cual comprende más de 70 cuartos al finalizar esta fase (Campaña Valenzuela y Boucher 2002; Campaña Valenzuela et al., 2000, 2001). $\mathrm{Si}$, en el pasado, varios investigadores han considerado Becán como la posible cabecera de la región Río Bec, bien podría haber ocurrido durante la segunda mitad del Clásico Tardío, dado el volumen de las construcciones y la cantidad de palacios construidos. Sin embargo, a pesar de la abundancia de construcciones elitistas, no se ha podido identificar en Becán, ya sea en estelas, en la iconografía o en las sepulturas (casi ausentes), evidencia de un poder real, lo que lleva a preguntarse sobre la organización política en el sitio (¿poder compartido? ¿Alianza de linajes?).

En el resto de la región, esta fase Chintok reúne las producciones arquitectónicas más refinadas del estilo Río Bec y se caracteriza por la aparición de los edificios de dos torres y la difusión de las portadas zoomorfas, dos tipos de construcción que se relacionan clara y ostensiblemente con el poder, en este caso un poder espacial y socialmente muy circunscrito en las manos de linajes locales (Nondédéo y Patrois, 2010). En Chicanná se modifica el Palacio I (agregándole sus dos torres), mientras que se edifican el Palacio II y el Edificio XX (nivel inferior), ambos decorados con una portada integral (Carrasco, 1994: 150-152; Eaton, 1975: 134); en Hormiguero se construye, entre otros, el Palacio II, que reúne en un sólo edificio el concepto de las torres y el de la portada zoomorfa (Bueno, 1999). La misma tendencia se observa en la microrregión de Río Bec: allá registramos con mucha precisión la construcción de numerosas casas nobles y un edificio central, el cual es fundador de toda una serie de nuevos grupos: Grupo B, Estructura 6N2; Yaxek-Las Escobas, Estructura 4; Grupo N, Estructura 1; Grupo O, Estructura 2; Ocelote, Estructura 1; Thompson, Estructura 2, etc. (Nondédéo y Patrois, 2010; Arnauld, Forné y Dzul, 2007).

A un nivel más amplio, es también durante esta fase cuando empieza a difundirse la influencia Río Bec fuera de su territorio de origen, tal como lo hemos observado en un estudio que se llevó a cabo en la frontera oeste (Nondédéo, 2002, 2003). A partir de un análisis detallado del material cerámico procedente de los grupos monumentales de este sector, se pudo observar en la fase Chintok la fundación de nuevos asentamientos que colonizan sectores dejados en gran parte vacíos por los antiguos habitantes de tradición petenera (figura 4). La progresión hacia el oeste de esta expansión Río Bec se pudo trazar gracias a la presencia en los asentamientos más occidentales de marcadores cerámicos fiables de la fase Chintok (grupo Traino, entre otros), que se encontraban en los niveles inferiores de los rellenos constructivos de los patios. Asimismo, se destacaba en estos mismos grupos la ausencia de marcadores característicos de la fase anterior (grupo Becanchén). Si consideramos ahora los datos desde una perspectiva macrorregional, sería tal vez al final de este mismo periodo cuando, 


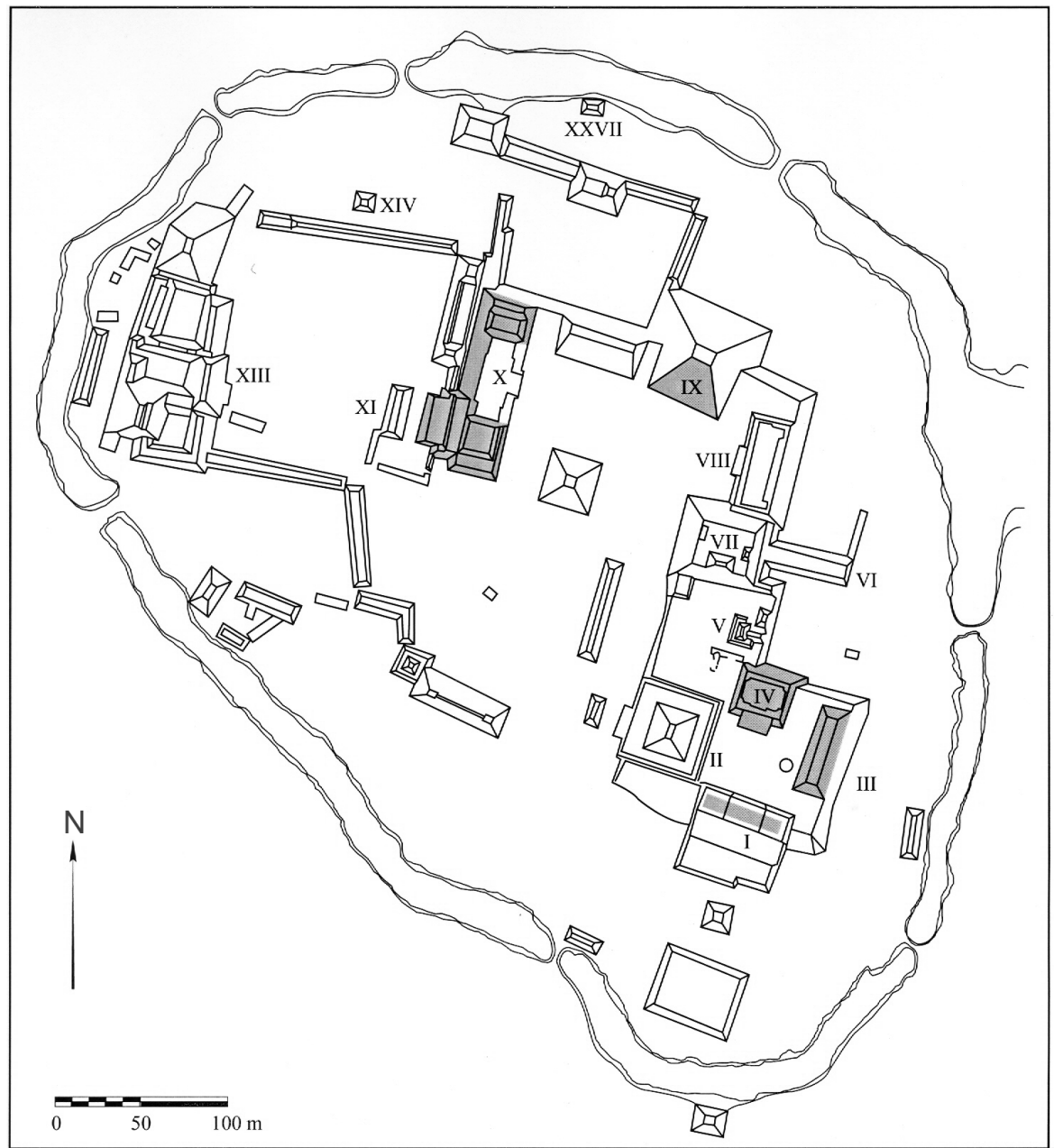

Figura 3c. Becán durante el Clásico Tardío (fase Chintok: 730-830 d.C.)

por primera vez, aparecerían en Calakmul los indicios de una influencia Río Bec perceptible en unos cuantos elementos arquitectónicos (moldura basal) y/o tipos cerámicos (Paakzatz modelado) (Carrasco, 1996).

En el registro epigráfico, la segunda mitad del Clásico Tardío se distingue por un aumento de las estelas erigidas, sobre todo alrededor del año 800 d.C (cuatro de las once fechas registradas en la región se sitúan entre el 790 y el 805 d.C.). Esto podría indicar el resurgimiento, en algunos sectores de Río Bec, de señoríos locales con cierta autonomía política, aunque sea de alcance limitado, como lo muestra la iconografía bélica de las escasas estelas conservadas (Grupo V en 


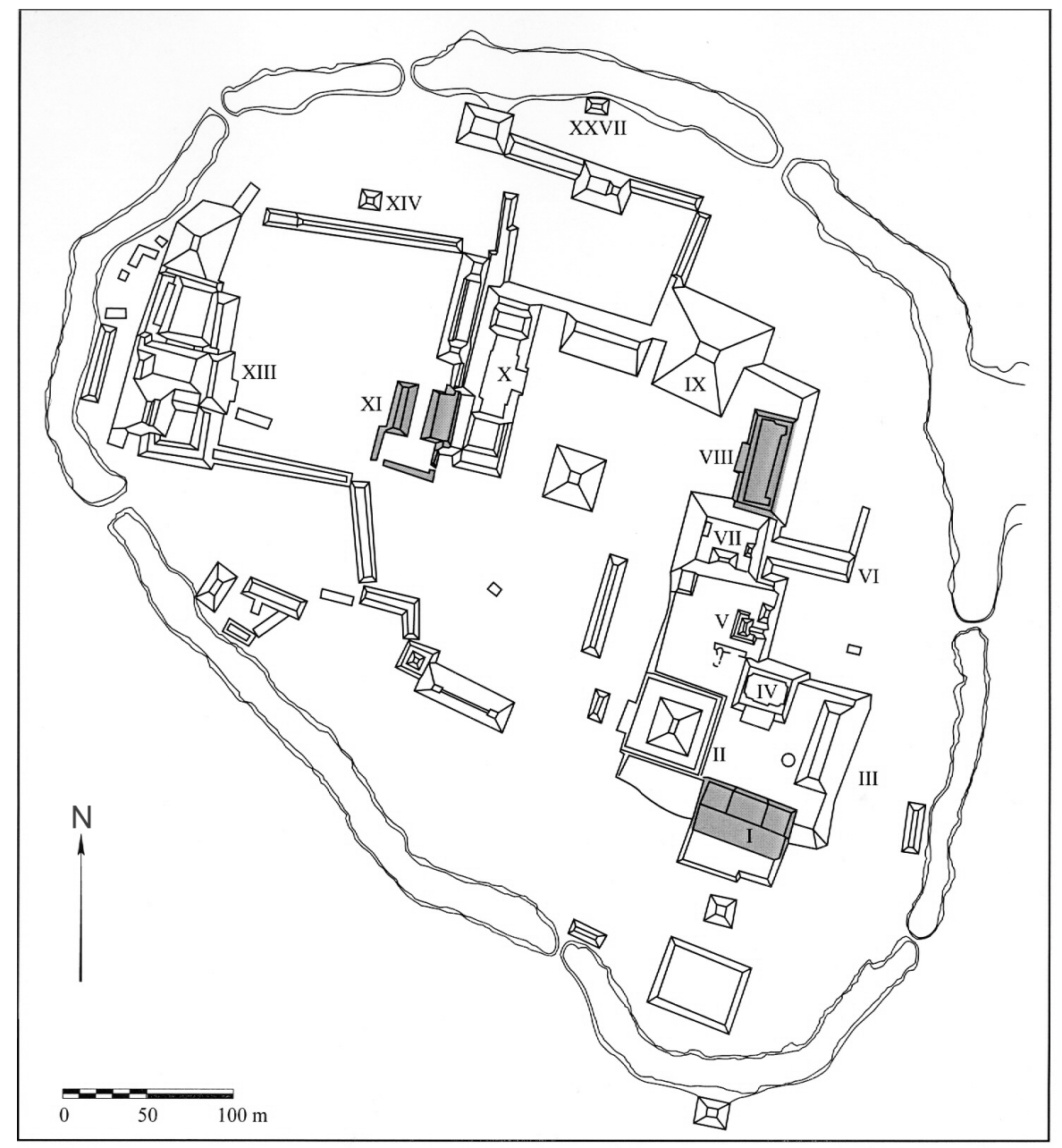

Figura 3d. Becán durante el Clásico Terminal (fase Xcocom temprano: 830-950 d.C.)

particular) en las que los gobernantes aparecen como guerreros asociados con cautivos. Estas estelas forman tal vez parte de la tendencia más general de emancipación política observada por Šprajc y Grube (2008: 274-275; Grube, 2005) en el sureste de Campeche, después de la caída de Kaan. Fuera lo que fuera, es en estas fechas y en este contexto que habría que situar, según Lacadena (2007), la aparición del posible glifo-emblema del sitio de Río Bec, presente tal vez en tres de sus asentamientos (Grupo II, V y Kajtún). Por otra parte, algunos de estos monumentos reflejan la instalación, al menos en la microrregión, de individuos o de una población originarios del norte de la península que utilizan palabras y 
sintaxis típicamente yucatecas y que manejan la Cuenta Corta (Arnauld y Lacadena, 2004; Nondédéo y Lacadena, 2004; Michelet, Nondédéo y Arnauld, 2005). Junto con estos marcadores linguiísticos, los datos cerámicos muestran también la introducción de nuevos tipos y técnicas cerámicas originarias del norte de la península (Ball, 1977: 134-135; Taladoire y Dzul, en prensa).

En la transición Clásico Tardío-Clásico Terminal, en la que se sitúa la aparición de estas influencias norteñas, hay que colocar el apogeo constructivo de la región. Una tendencia monumental se observa en cada sitio, la cual consiste en la construcción de amplios palacios en la cúspide de voluminosos basamentos o altas plataformas. Esta tendencia hacia lo masivo se ilustra en Becán a través de la edificación de las estructuras VIII y I, dos tipos de edificios que rompen con la tradición Río Bec de la fase anterior (figura 3d). La Estructura VIII en particular, con su antesala concebida como un pórtico abierto con columnas exentas de mampostería, podría reflejar el desarrollo de la función de reunión en ciertos edificios, tal como lo pudimos comprobar para estas fechas en la micro-región de Río Bec (Nondédéo y Patrois, 2010). En el resto de la región Río Bec, esta tendencia hacia lo monumental se encuentra en Xpuhil, con la construcción de las tres torres de la Estructura I; o en Chicanná, con la edificación de las fachadas este, norte y oeste de la Estructura XX (Bueno, 1999; Campaña Valenzuela, 2005; Carrasco, 1994). Otros asentamientos de la región, tal como Culucbalom o Payán, a pesar de la ausencia de datos cerámicos pueden también fecharse durante esta transición por la presencia de algunos detalles arquitectónicos (falsos nichos centrales en el eje de la entrada o intradoses rectilíneos), que aparecen al final del Clásico Tardío. En la microrregión de Río Bec, esta fase de transición (MakanXpuhuk, alrededor del 850 d.C.) corresponde a un apogeo constructivo que impulsó la edificación de la mayoría de los edificios de dos torres o decorados con portadas zoomorfas: Grupo I, Estructuras XI y XV-XVII; Grupo V, Estructura V; Omelita, Estructura 1; Grupo IV, Estructura 2; Grupo E, Estructura 1; Grupo M, Estructura 1; Ceibarico A, Estructura 1; Grupo B, Estructura 6N1 (con sus torres), junto con la construcción del monumental Edificio A (Nondédéo y Dzul, 2007, en prensa; Nondédéo y Patrois, 2010; Michelet et al. 2007).

El dinamismo excepcional de los sitios al iniciar el Clásico Terminal podría explicar por qué, frente a un mundo en plena recomposición política después de la caída de Kaan y frente a los primeros signos del colapso en las Tierras Bajas Centrales, esta región Río Bec destaca como un foco cultural y empieza a difundir sus rasgos fuera de su territorio, constituyendo una especie de horizonte Río Bec el cual abarca buena parte del sur de la península (Nondédéo, 2003; Arnauld y Nondédéo, 2010). Por una parte, se trata de influencias puntuales en sitios como El Tigre, Kohunlich, Calakmul, Oxpemul ${ }^{6}$ y posiblemente Naachtún, en los que se copian algunos detalles arquitectónicos y estilísticos integrándolos a una

\footnotetext{
${ }^{6}$ Observación personal (2005 y 2008), en varios sectores de la Estructura XII, de pequeños sillares cuadrados perfectamente labrados que recuerdan los de tradición Río Bec.
} 


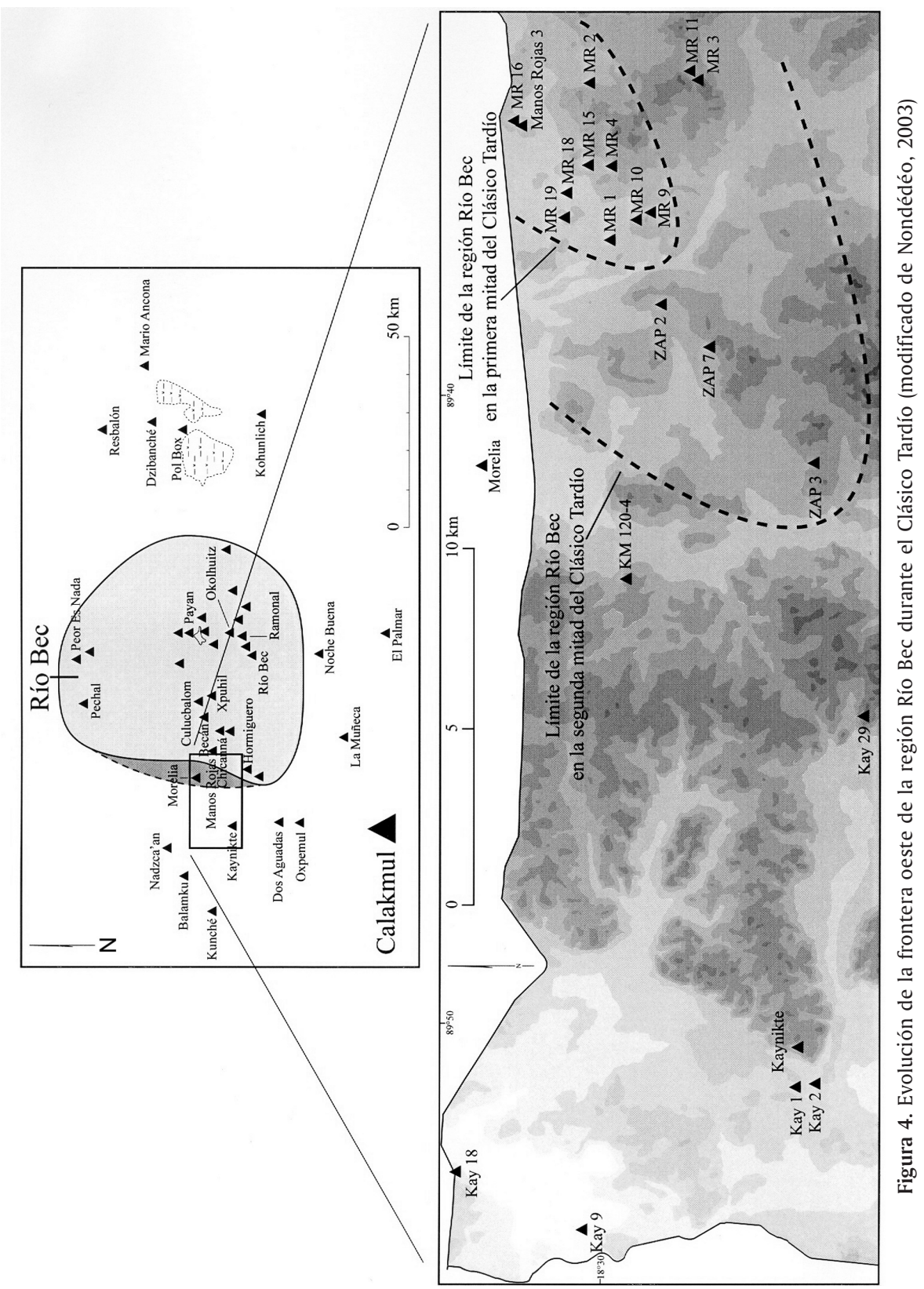


tradición local existente (Vargas y Delgado, 2003; Nalda, 2005; Carrasco, 1996; Reese-Taylor, et al. 2005). Esta primera clase de influencias indica la atracción y el resplandor que conoce Río Bec en el Clásico Terminal, mismos que incitan a los demás centros a reproducir algunos de sus rasgos más representativos, un poco en el marco del concepto de "estilo internacional" establecido por Blanton et al. (1996) (figura 5).

Por otra parte, y en otros casos como Balamkú, Nadzca'an o Morelia (Michelet et al., 1998; Pescador, 1998; Nondédéo, 2003), y posiblemente otros más como Kunché (Andrews IV, 1943), se trata de la instalación de algunos habitantes de origen Río Bec, quienes traen consigo un conjunto de rasgos típicos de dicha región, perceptibles en la organización en patio, la arquitectura de sillares cuadrados finamente labrados y colocados a "junta seca", la planta tripartita en los edificios, el registro iconográfico o las tradiciones cerámicas. Esta serie de rasgos habla de una expansión Río Bec fuera de los límites originales de la región, cuyos habitantes vienen a volver a ocupar antiguos sitios de tradición petenera, instalándose en medio de edificios en ruina y asimilando una población local aún in situ. Esta difusión de los rasgos Río Bec podría reflejar una estrategia de las élites de esta región, deseosas de establecer redes de alianzas a larga distancia para fortalecer su preeminencia a nivel local en un contexto de fuerte competición y emulación entre las numerosas casas nobles existentes al final del Clásico Tardío (Blanton et al., 1996). A la par de esta expansión Río Bec por medio de alianzas de toda índole, se produce una apertura de la región al resto del área maya, fenómeno que se observa claramente en la reanudación del acceso a redes de intercambio. Así, hacia el final del Clásico Tardío y durante el Clásico Terminal la región recibe importaciones, en particular de obsidiana y de pedernal café, así como de pastas finas y de cerámica plomiza (Andrieu, 2007, 2009: 113, 354-355; Ball, 1977; Rovner y Lewenstein, 1997; Taladoire y Dzul, en prensa). Sin embargo, y a diferencia del modelo de Blanton (et al., 1996), el análisis minucioso del Grupo B de Río Bec no ha permitido comprobar un acceso diferenciado a los bienes importados según la jerarquía social de los edificios (Andrieu, 2007, 2009: 305).

Durante la primera mitad del Clásico Terminal, la ocupación en la región se mantiene dinámica: se han documentado varias construcciones en Xpuhil (Estructuras II y II-a; Estructura I de Xpuhil II), Hormiguero (Estructuras V y VI), Chicanná (el nivel superior de la Estructura XX, la Estructura III-a; el anexo de la Estructura VI) o en Manos Rojas C, mientras que en Becán, fuera de las remodelaciones en las Estructuras II, III, X o de la edificación del nivel inferior de cuartos en la Estructura IV, merece subrayarse la ampliación del juego de pelota (el cual se dota de zonas terminales), uno de los pocos, si no el único en uso a nivel regional para ese periodo, lo que traduce tal vez cierta preeminencia de Becán frente a los demás asentamientos Río Bec (Bueno, 1999; Cantero, 1998; Campaña et al., 2001; Carrasco, 1994; Potter, 1977). En algunas de las construcciones citadas aparecen los mascarones de ángulo que decoran esquinas de los edificios, pero 


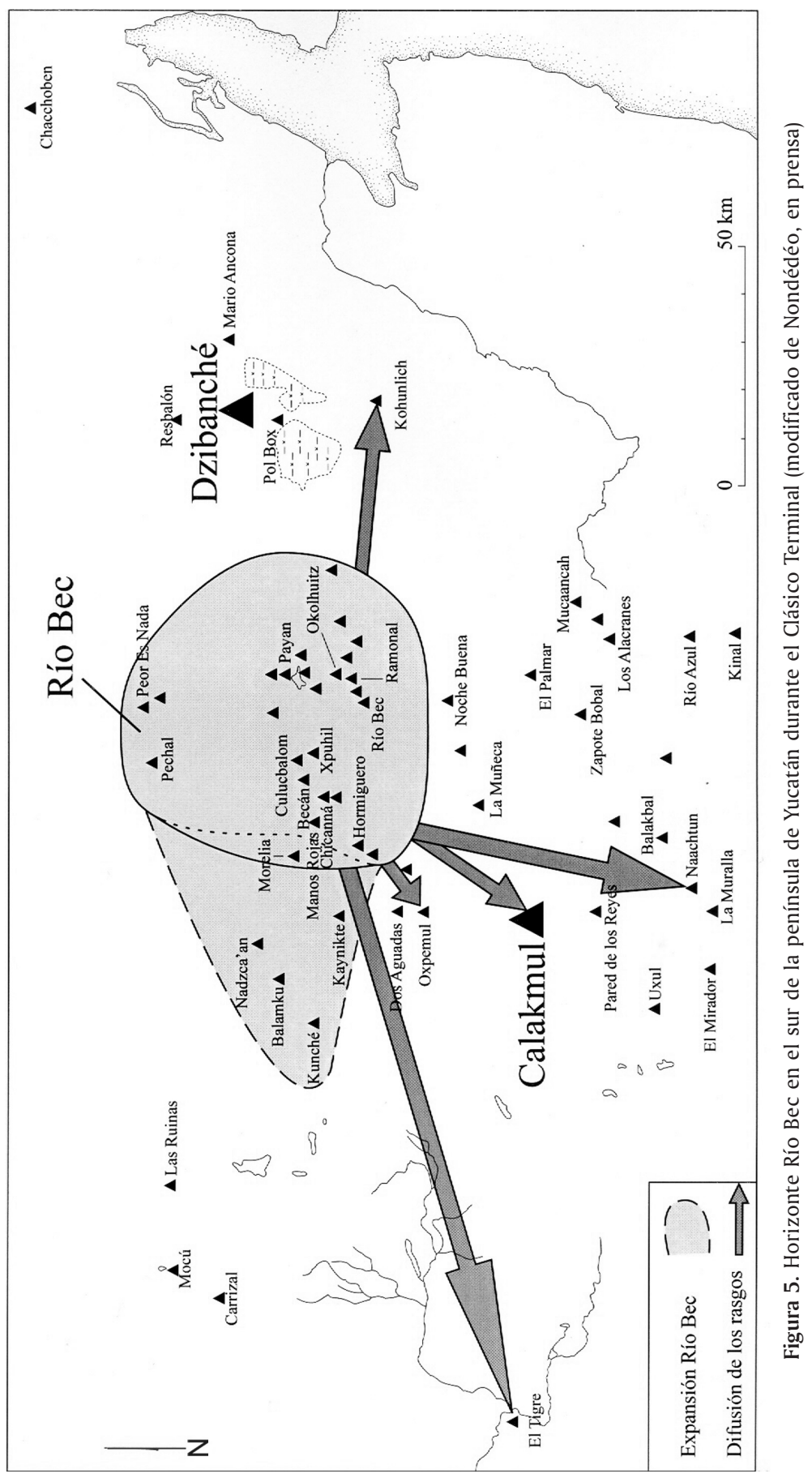


que no hemos registrado en la microrregión de Río Bec. Ahí, las construcciones de esta fase (Xpuhuk 1, 850-950 d.C.) se encuentran un poco más escasas y consisten tanto en edificios sencillos de dos cuartos como edificios monumentales de dos torres: Grupo III, Estructura I; Grupo I, Estructura I; La Tortuga, Estructura I; Grupo V, Estructura I; Tres Lunas, Estructura I; El Porvenir, Estructuras I, II y V. Se distinguen sobre todo por un aumento de las decoraciones en las fachadas (Nondédéo y Dzul, 2007; Nondédéo y Patrois, 2010).

De manera general, la región Río Bec parece integrarse ahora a las tendencias macrorregionales. Una prueba de esta nueva inclusión en el desarrollo de las Tierras Bajas sería la dedicación de estelas con fechas tardías —en particular en Pasión del Cristo, Río Bec V o en Pechal-, ya que la misma tendencia se observa en varios sitios del Petén campechano: de Oxpemul a La Muñeca pasando por Nadzca'an (Ruppert y Denison, 1943; Martin y Grube, 2000: 115; Grube, 2008). A partir del 950 d.C., la región empieza a declinar fuertemente, se abandonan numerosos asentamientos y se registra muy poca actividad, con excepción de Becán (Estructura I-a y I-b) y de Xpuhil (Estructuras III y IV) donde la ocupación parece mantenerse hasta el 1050 o el 1100 d.C. (Campaña Valenzuela et al., 2004; Bueno, 1999). Sin embargo, la región no se vacía completamente de sus habitantes. Fuera de los numerosos fragmentos de incensarios del Postclásico encontrados en cada sitio o de los grafitos postabandono registrados en los edificios en ruinas (Patrois y Nondédéo, 2009), existen testimonios de una ocupación sedentaria en la Isla Cilvituk, en Balamkú o en Dzibanché entre otros ejemplos (Andrews IV, 1943; Becquelin et al., 1999; Nalda y Balanzario, 2005).

\section{Conclusión}

Con base en los datos arqueológicos disponibles y en ausencia de información epigráfica relevante, fuera de las escasas fechas que se pudieron reconstruir, la historia del fenómeno Río Bec parece desarrollarse, desde su gestación y hasta su apogeo, de manera paralela al reino de Kaan, pero independientemente de él. Estamos frente a un desarrollo bastante linear, sin rupturas que pudieran relacionarse con las altas y bajas del reino de Kaan. Sin embargo, el debilitamiento de Kaan y la pérdida progresiva de su control regional podrían haber favorecido la difusión de ciertos rasgos Río Bec hacia centros más alejados.

Para tratar de entender el porqué del posible desinterés de Kaan hacia la región Río Bec, uno tendría que partir de su patrón de asentamiento muy disperso y organización sociopolítica atomizada: allí, el poder siempre limitado parece haber estado en las manos de un sinnúmero de casas nobles, cada una encabezada por una familia establecida en un grupo monumental. La relativa autonomía de cada una, en ausencia de un control jerárquico superior aparente, no habría constituido una amenaza para Calakmul, ni le habría incitado a extender su dominio sobre ellas. En términos de inversión política, más valía para Calakmul 
buscar ampliar su red de alianzas/control sobre las élites que dominaban sitios estratégicos asociados con territorios y/o reinos importantes, que interesarse en las casas nobles de Río Bec controladas por grupos sociales jerárquicamente inferiores. El único factor que habría justificado una intervención de Calakmul en la región hubiera sido el control político que Becán hubiera tenido en relación a estas casas que mencionamos, pero no existen datos al respecto. En parte por las mismas razones, la región Río Bec no habría sido digna de interés (ni siquiera estratégico desde la perspectiva de las alianzas) para un sitio como Tikal en el marco de su reconquista de cierta hegemonía frente a Calakmul. Río Bec aparece entonces como una región un poco marginal política y económicamente para la dinastía Kaan, cuyos intereses estratégicos se encuentran en el Petén Central y en el Usumacinta. Esta localización de Río Bec al margen del escenario de enfrentamiento Tikal-Calakmul tal vez podría explicar por qué esta región no tuvo acceso a bienes y redes de intercambio.

Este desinterés que percibimos por parte de Calakmul sobre la región Río Bec lo traduce implícitamente la epigrafía: ésta nos indica que las relaciones políticas que desarrolló la capital de Kaan durante el Clásico Tardío se orientaban exclusivamente hacia el sur y el suroeste de las Tierras Bajas (Martin, 2009). Estas miradas casi exclusivas de Calakmul hacia el Petén son confirmadas por los análisis isotópicos efectuados en los restos óseos de la capital, los cuales indican movimientos de población y afinidades principalmente con el sur de las Tierras Bajas (Tiesler y Cucina, 2009).

\section{BIBLIOGRAFÍA}

Andrews IV, E. Wyllys

1943 The Archaeology of Southwestern Campeche. Washington: Carnegie Institution of Washington (Publication 546, Contribution 40).

Andrieu, Chloé

2007 "Una perspectiva regional de la economía lítica de Río Bec". Ponencia presentada en la mesa "Río Bec: Génesis, desarrollo y percepción de un fenómeno cultural”, Philippe Nondédéo (coord.), VII Congreso Internacional de los Mayistas, 8-14 de julio de 2007. Mérida, Yucatán.

2009 Outils mayas: distribution et production du silex et de l'obsidienne dans les Basses Terres. Tesis doctoral, París: Université Paris Ouest-Nanterre-La Défense, ms.

Arnauld, Marie-Charlotte y Alfonso Lacadena

2004 "Asentar su autoridad: banquetas en el Grupo B de Río Bec (Campeche, México)”, Journal de la Société des Américanistes 90 (1): 203-222. París: Société des Américanistes.

Arnauld, Marie-Charlotte y Philippe Nondédéo

2010 "Rio Bec between the Central and the Northern Lowlands", The Maya and their Neighbours: Internal and External Contacts Through Time. Proceedings of the 
10th European Maya Conference, Leiden, December 9-10, 2005. L. van Broekhoven, R. Valencia R., B. Vis y F. Sachse (coord.), pp. 43-59. Markt Schwaben, Alemania: Verlag Anton Saurwein (Acta Mesoamericana, 22).

Arnauld, Marie-Charlotte, Mélanie Forné y Sara Dzul

2007 "Dinámica entre unidades sociales vecinas: los Grupos A, B y D de Río Bec". Ponencia presentada en la mesa "Río Bec: Génesis, desarrollo y percepción de un fenómeno cultural”, Philippe Nondédéo (coord.), VII Congreso Internacional de Mayistas, 8-14 de julio de 2007. Mérida, Yucatán.

Ball, Joseph

1977 The archaeological ceramics of Becán, Campeche, Mexico. Nueva Orleans: Tulane University (Middle American Research Institute, Publication 43).

Ball, Joseph y E. Wyllys Andrews V

1978 "Preclassic Architecture at Becán, Campeche, Mexico", Middle American Research Institute, Occasional Papers 3, pp. 1-17. Nueva Orleans: Tulane University.

Becquelin, Pierre, Dominique Michelet, Gregory Pereira, Fabienne de Pierrebourg, Éva Lemmonier y Éric Taladoire,

1999 "Proyecto de investigación arqueológica 'Del Clásico Temprano al Clásico Reciente en Balamkú' (4a temporada 1999). Informe de los trabajos de campo realizados del 22 de febrero al 30 de marzo de 1999". Archivo Técnico del Consejo de Arqueología. México: Instituto Nacional de Antropología e Historia. Manuscrito.

Beliaev, Dmitri y Alexander Safronov

2002 "Kanal Kings in Quintana Roo". Manuscrito.

Blanton Richard, Gary Feinman, Stephen Kowalewski y Meter Peregrine

1996 "A Dual-Processual Theory for the Evolution of Mesoamerican Civilization", Current Anthropology, 37 (1): 1-14. Chicago: The University of Chicago Press.

Boucher, Sylviane, Yoly Palomo y Luz Evelia Campaña V.

2004 "Dramatis Personae de la ofrenda funeraria en la estructura IX de Becán, Campeche”, Culto funerario en la sociedad maya, Memoria de la Cuarta Mesa Redonda de Palenque, pp. 369-394. Rafael Cobos (ed.). México: Instituto Nacional de Antropología e Historia.

Bueno, Ricardo

1987 "Informe preliminar sobre el grupo este de Hormiguero", Cuadernos de Arquitectura Mesoamericana, 10: 96. México: Universidad Nacional Autónoma de México, Facultad de Arquitectura.

1989 “Excavaciones en la región Río Bec 1984-1985”. Tesis de licenciatura en Arqueología, México: Escuela Nacional de Antropología e Historia. 
Bueno, Ricardo

1991 "El sitio arqueológico de Hormiguero" en Cuadernos de Arquitectura Mesoamericana 12: 35-40. México: Universidad Nacional Autónoma de México, Facultad de Arquitectura.

1999 Entre un río de robles, un acercamiento a la arqueología de la región Río Bec. México: Instituto Nacional de Antropología e Historia (Colección Científica, 411).

Bueno, Ricardo et al.

1992 "Proyecto arqueológico del Sur de Campeche. Reporte preliminar de las excavaciones en la región Río Bec 1992 (octubre 91-septiembre 92)". Archivo Técnico del Consejo de Arqueología. México: Instituto Nacional de Antropología e Historia. Manuscrito.

Campaña Valenzuela, Luz E.

2005 “Contribuciones a la historia de Becán”, Arqueología Mexicana, XIII (75): 4853. México: Consejo Nacional para la Cultura y las Artes/Raíces.

Campaña Valenzuela, Luz E. y Sylviane Boucher

2002 “Nuevas imágenes de Becán, Campeche”, Arqueología Mexicana, X, (56): 64-

69. México: Consejo Nacional para la Cultura y las Artes/Raíces.

Campaña Valenzuela, Luz E. y Vera Tiesler B.

2004 "Sacrificio y tratamiento ritual del cuerpo humano en la antigua sociedad maya: el caso del depósito E-1003 de Becán, Campeche”. Arqueología, 33: 32-46. México: Instituto Nacional de Antropología e Historia.

Campaña Valenzuela, Luz E., Victoria Bojórquez Diego, Claudia García Solís, Valeria García Vierna, Paola Lozano Vega, Leonardo Santoyo Alonso y Laura Solar Valverde

2000 "Proyecto arqueológico Becán: informe anual de la temporada de campo 1999-2000”, Luz E. Campaña V. (coord.). Archivo del Consejo de Arqueología. México: Instituto Nacional de Antropología e Historia. Manuscrito.

Campaña Valenzuela, Luz E., Edwin Angulo Torres, Sara Dzul Góngora y Claudia García Solís 2001 "Proyecto arqueológico Becán: informe anual de la temporada de campo 2000-2001", Luz E. Campaña V. (coord.). Archivo del Consejo de Arqueología. México: Instituto Nacional de Antropología e Historia. Manuscrito.

Campaña Valenzuela, Luz E., Edwin Angulo Torres, Kenichiro Tsukamoto y Yareli Jáidar Benavides

2004 "Proyecto arqueológico Becán: informe anual de la temporada de campo 2003-2004", Luz E. Campaña V. (coord.). Archivo del Consejo de Arqueología. México: Instituto Nacional de Antropología e Historia. Manuscrito.

Cantero, Ángeles

1998 "Proyecto arqueológico Hormiguero. Informe de la temporada 1998". México: Instituto Nacional de Antropología e Historia, Archivo Técnico del Consejo de Arqueología. Manuscrito. 
Carrasco, Ramón

1994 Chicanná, Campeche, un sitio de la frontera sur. Estudio arquitectónico. México: Universidad Nacional Autónoma de México, Instituto de Investigaciones Filológicas, Centro de Estudios Mayas.

1996 “Calakmul, Campeche”. Arqueología Mexicana, III (18): 46-51. México: Consejo Nacional para la Cultura y las Artes/Raíces.

Carrasco, Ramón y Marines Colón

2005 "El reino de Kaan y la antigua ciudad maya de Calakmul". Arqueología Mexicana, XIII (75): 40-47. México: Consejo Nacional para la Cultura y las Artes / Raíces.

Eaton, Jack D.

1975 "Chicanná: an elite center in the Rio Bec region", Preliminary Reports on Archaeological Investigations in the Rio Bec Area, Campeche, Mexico, pp. 133-138. Nueva Orleans: Tulane University, Middle American Research Institute.

Esparza Olguín, Octavio y Vania Pérez Gutiérrez

2009 "Archaeological and Epigraphic Studies in Pol Box, Quintana Roo", The PARI Journal, 9 (3): 1-16. San Francisco: Pre-columbian Art Research Institute.

Grube, Nicolai

2004 “El origen de la dinastía Kaah”, Los cautivos de Dzibanché, pp. 114-131, Enrique Nalda (ed.). México: Instituto Nacional de Antropología e Historia.

2005 "Toponyms, Emblem Glyphs, and the Political Geography of Southern Campeche". Anthopological Notebooks, 11: 87-100. Ljubljana, Eslovenia: Društvo Antropologov Slovenije.

2008 "Monumentos esculpidos: epigrafía e iconografía”, Reconocimiento arqueológico en el sureste del estado de Campeche: 1996-2005, pp. 177-231, Ivan Sprajc (coord.), Oxford: Archeopress (British Archaeological Reports, International Series 1742 / Paris Monographs in American Archaeology).

Lacadena, Alfonso

2007 "Las inscripciones de Río Bec". Ponencia presentada en la mesa "Río Bec: Génesis, desarrollo y percepción de un fenómeno cultural”, Philippe Nondédéo (coord.), VII Congreso Internacional de Mayistas, 8-14 de julio de 2007. Mérida, Yucatán.

Martin, Simon

2005 "Of Snakes and Bats", The PARI Journal, 6 (2): 5-15. San Francisco: Pre-columbian Art Research Institute.

2009 "Tentacles of the Serpent State". Ponencia presentada en la mesa "Nuevas perspectivas en torno a la Organización Sociopolítica de las tierras bajas del Sur en el Clásico tardío: El reino de Kaan”, Verónica Vázquez López y Ana García Barrios (coord.), 53 Congreso Internacional de Americanistas, 19-24 de julio de 2009. México. Manuscrito. 
Martin, Simon y Nicolai Grube

$2000 \quad$ Chronicle of the Maya Kings and Queens. Deciphering the Dynasties of the Ancient Maya. Londres: Thames and Hudson.

Messenger, Lewis C., Jr.

1975 Project Becán 1974: results of archaeological activity in the Río Bec region. Tesis de maestría. Cholula: Universidad de las Américas.

Michelet, Dominique et al.

1998 "La saison de fouille de 1998 à Balamkú (Campeche, Méxique): des avancées substantielles", Journal de la Société des Américanistes, 84 (1): 183-199. París: Société des Américanistes

2007 "El grupo A de Río Bec: historia y funciones de un edificio de dos torres". Ponencia presentada en la mesa "Río Bec: Génesis, desarrollo y percepción de un fenómeno cultural”, Philippe Nondédéo (coord.), VII Congreso Internacional de Mayistas, 8-14 de julio de 2007. Mérida, Yucatán. Manuscrito.

Michelet, Dominique, Philippe Nondédéo y Charlotte Arnauld

2005 "Río Bec, ¿una excepción?” Arqueología Mexicana, XIII (75): 58-63. México: Consejo Nacional para la Cultura y las Artes/Raíces.

Nalda, Enrique

2005 “Kohunlich and Dzibanché: Parallel Histories”, Quintana Roo Archaeology, pp. 228-246, J. Shaw y J. P. Mathews (coord.). Tucson, Arizona: The University of Arizona Press.

2010 "Los templos de las pilastras pareadas: una variante arquitectónica del Clásico medio de Dzibanché", Figuras mayas de la diversidad, A. Monod-Becquelin, A. Breton y M. H. Ruz (coord.), pp. 453-478. Mérida: Universidad Nacional Autónoma de México, Centro Peninsular en Humanidades y Ciencias Sociales/Centre National de la Recherche Scientifique.

Nalda, Enrique (ed.)

2004 Los cautivos de Dzibanché. México: Instituto Nacional de Antropología e Historia.

Nalda, Enrique y Sadra Balanzario

2005 "Kohunlich y Dzibanché: los últimos años de investigación”. Arqueología Mexicana, XIII (76): 42-47. México: Consejo Nacional para la Cultura y las Artes / Raíces.

2008 "Un estilo arquitectónico peculiar en Dzibanché y su posible correlato territorial”, El territorio maya, pp. 303-321, Rodrigo Liendo Stuardo (coord.). México: Instituto Nacional de Antropología e Historia (Memoria de la Quinta Mesa Redonda de Palenque).

Nondédéo, Philippe

2002 "La zona Río Bec frente a las influencias Petén en el sur del Estado de Campeche: propuesta para la definición de una zona fronteriza”, Los Investigadores de la Cultura Maya, X (1): 42-52. Campeche: Universidad Autónoma de Campeche. 
Nondédéo, Philippe

2003 L'évolution des sites mayas du sud de l'Etat du Campeche, Mexique. Oxford: Archeopress (British Archaeological Reports, International Series 1171/Paris Monographs in American Archaeology).

En prensa "La región maya de Río Bec: reevaluación del concepto de sitio y definición de un patrón de asentamiento atípico", El urbanismo en Mesoamérica /Urbanism in Mesoamerica, W. T., Sanders y G. Cobean (eds.), vol. 3. Pennsylvania: PennState University, University Park.

Nondédéo, Philippe y Sara Dzul

2007 "Secuencia arquitectónica y ocupación en la micro-región de Río Bec”. Ponencia presentada en la mesa "Río Bec: Génesis, desarrollo y percepción de un fenómeno cultural”, Philippe Nondédéo (coord.), VII Congreso Internacional de Mayistas, 8-14 de julio de 2007, Mérida, Yucatán. Manuscrito.

En prensa "Arquitectura y cronología: hacia un esquema preliminar de evolución de la ocupación en la microrregión de Río Bec", La península de Yucatán: investigaciones recientes y cronologías alternativas, Antonio Benavides C. y Ernesto Vargas P. (eds). Campeche: Universidad Autónoma de Campeche.

Nondédéo, Philippe y Alfonso Lacadena

2004 "Kajtún: un nuevo sitio maya con monumentos esculpidos en la región Río Bec”, Journal de la Société des Américanistes, 90 (1): 183-201. París: Société des Américanistes.

Nondédéo, Philippe y Julie Patrois

2007 "Iconografía del poder en la zona Río Bec: del modo de representación a las primeras interpretaciones", El patrimonio arqueológico maya en Campeche, pp. 159-205, Ernesto Vargas y Antonio Benavides (coord.). México: Universidad Nacional Autónoma de México, Instituto de Investigaciones Filológicas, Centro de Estudios Mayas (Cuadernos, 35).

2010 "Variaciones en la morfología y la decoración de los edificios mayores de Río Bec: en busca de un significado", Figuras mayas de la diversidad, A. Monod-Becquelin, A. Breton y M. H. Ruz (coord.), pp. 305-334. Mérida: Universidad Nacional Autónoma de México, Centro Peninsular en Humanidades y Ciencias Sociales/Centre National de la Recherche Scientifique.

Patrois, Julie y Philippe Nondédéo

2009 "Los grafitos mayas prehispánicos en la micro-región de Río Bec (Campeche, México)”, Los grafitos mayas, pp. 29-60, Cristina Vidal y Gaspar Muñoz (coord.). Valencia: Universidad Politécnica de Valencia.

Pescador C., Laura

1998 “Nadzca'an”. Journal de la Société des Américanistes, 84 (1): 167-182. París: Société des Américanistes.

Potter, David F.

1977 Maya Architecture of the Central Yucatan Peninsula. Nueva Orleans: Tulane University (Middle American Research Institute, Publication 44). 
Reese-Taylor, Kathryn et al.

2005 "Proyecto arqueológico Naachtun: Resultados preliminares de la primera temporada de campo 2004", XVIII Simposio de Investigaciones Arqueológicas en Guatemala, 2004, pp. 85-94, J. P. Laporte, B. Arroyo y H. Mejia (coord). Guatemala: Museo Nacional de Arqueología y Etnología.

Rovner, Irvin y Susan M. Lewenstein

1997 Maya stone tools of Dzibilchaltun, Yucatan, and Becan and Chicanna, Campeche. Nueva Orleans: Tulane University (Middle American Research Institute, Publication 65).

Reyes Ayala, Claudia

2006 "Análisis estilístico del friso de la estructura XX de Calakmul”, Los Investigadores de la Cultura Maya, 14 (2): 359-370. Campeche: Universidad Autónoma de Campeche.

Ruppert, Karl y John H. Denison

1943 Archaeological reconnaissance in Campeche, Quintana Roo and Peten. Washington, D. C.: Carnegie Institution of Washington (Publication 543).

Šprajc, Ivan y Nicolai Grube

2008 "Arqueología del sureste de Campeche: una síntesis", Reconocimiento arqueológico en el sureste de Campeche, México: 1996-2005, pp. 263-275, Ivan Sprajc (coord.). Oxford: Archeopress (British Archaeological Reports, International Series 1742 / Paris Monographs in American Archaeology).

Stoltman, John B.

1978 "Lithic artefacts from a complex society: the chipped stone tools of Becán, Campeche, México". Middle American Research Institute, Occasional Papers, 2: 3-30. Nueva Orleans: Tulane University.

Taladoire, Eric

2007 "Posibles implicaciones de la ocupación espacial en Río Bec a partir de la cronología”. Manuscrito.

2009 “Terrains de jeu et stèles dans la région de Río Bec: rejet ou inutilité?”. Manuscrito.

Taladoire, Eric y Sara Dzul

En prensa "Sondeos estratigráficos y fechamientos en la zona nuclear de Río Bec: primeros resultados”, La península de Yucatán: investigaciones recientes y cronologías alternativas, Antonio Benavides C. y Ernesto Vargas P. (eds.). Campeche: Universidad Autónoma de Campeche.

Thomas, Prentice M., Jr.

1981 Prehistoric Maya Settlement Patterns at Becán, Campeche, Mexico. Nueva Orleans: Tulane University (Middle American Research Institute, Publication 45). 
Tiesler, Vera y Andrea Cucina

2009 "Filiación, relaciones inter-poblacionales y patrones migratorios en el Petén Central durante el Clásico". Ponencia presentada en la mesa "Nuevas perspectivas en torno a la Organización Sociopolítica de las tierras bajas del Sur en el Clásico tardío: El reino de Kaan”, Verónica Vázquez López y Ana García Barrios (coord.), 53 Congreso Internacional de Americanistas, 19-24 julio de 2009. México. Manuscrito.

Vargas P., Ernesto y Angélica Delgado S.

2003 "El Clásico Terminal en El Tigre, Campeche”, Los Investigadores de la Cultura Maya, XI (2): 406-423. Campeche: Universidad Autónoma de Campeche.

Velásquez García, Erik

2004 "Los escalones jeroglíficos de Dzibanché", Los cautivos de Dzibanché, pp. 78-103, Enrique Nalda (ed.). México: Instituto Nacional de Antropología e Historia.

2008 "Los posibles alcances territoriales de la influencia política de Dzibanché durante el Clásico temprano: nuevas alternativas para interpretar las menciones históricas sobre la entidad política de Kan”, El territorio maya, pp. 323-352, Rodrigo Liendo Stuardo (coord.). México: Instituto Nacional de Antropología e Historia (Memoria de la Quinta Mesa Redonda de Palenque).

Webster, David

1976 Defensive Earthworks at Becan, Campeche, Mexico. Implications for Maya Warfare. Nueva Orleans: Tulane University (Middle American Research Institute, Publication 41). 